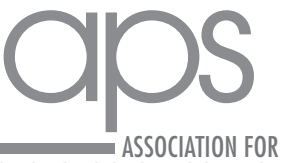

\section{Understanding Desire for Food and Drink: A Grounded-Cognition Approach}

\author{
Esther K. Papies $(\mathbb{D}$, Lawrence W. Barsalou $\mathbb{D}$, and Dorottya Rusz \\ Institute of Neuroscience and Psychology, University of Glasgow
}

Current Directions in Psychological Science

2020, Vol. 29(2) 193-198

(C) The Author(s) 2020

(c) (i)

Article reuse guidelines: sagepub.com/journals-permissions DOI: $10.1177 / 0963721420904958$ www.psychologicalscience.org/CDPS (9SAGE

\begin{abstract}
How does desire for food and drink arise in the human mind? We suggest that rewarding simulations, which are based on previous experiences, play a key role. In other words, people think about food and drink in terms of what it feels like to consume them, and this leads to desire. We illustrate this with research using behavioral, physiological, and neuroimaging methods. This work shows that food and drink cues (e.g., words, eating contexts, labels) trigger spontaneous eating and drinking simulations (e.g., thoughts about taste, texture, and enjoyment) and that these simulations affect desire and eating experiences (e.g., cravings, salivation, taste ratings). These simulations can be disrupted or diffused through working memory load or through mindfulness, thus reducing desire. We discuss these findings in the context of simulations in motivated behavior more generally and suggest directions for future research.
\end{abstract}

\title{
Keywords
}

grounded cognition, simulation, desire, self-regulation, food

How does desire for food and drink develop in the cognitive system? Can a better understanding of these processes help to tame unwanted desires? People typically experience a variety of desires throughout the day, especially for food and drink (Hofmann, Vohs, \& Baumeister, 2012). We define desire as the conscious or unconscious state of motivation for a specific stimulus or experience that is anticipated to be rewarding (Papies \& Barsalou, 2015). Often, these desires favor short-term hedonic goals over long-term investment goals, such as a high-calorie snack over heart health or another late-night drink over the next day's productivity. This can ultimately lead to a range of noncommunicable diseases such as obesity and cancer. Being able to diffuse short-term desires has considerable potential to improve health and well-being.

\section{A Grounded-Cognition Theory of Desire}

The grounded-cognition theory of desire focuses on the role of basic cognitive and memory processes in explaining how external cues lead to desire and motivated behavior (Papies, 2020; Papies \& Barsalou, 2015; Papies, Best, Gelibter, \& Barsalou, 2017; Papies, Pronk, Keesman, \& Barsalou, 2015). Although other work has shown, for example, how factors such as personality traits, physiological processes, social norms, and working memory processes affect food intake, no previous research has provided an integrated account of how motivation for specific foods and drinks arises in the cognitive system. Research on grounded processes in cognition in general suggests that our knowledge about the world is represented by typically nonconscious simulations, or partial reenactments, of perceptual experiences in the relevant sensory modalities (e.g., taste, vision; Barsalou, 2008, 2009). As an example, when a person thinks about an object such as a hammer, this activates the same brain areas that are involved when the person looks at, holds, or uses a hammer (e.g., Martin, Wiggs, Ungerleider, \& Haxby, 1996). These automatic simulations help to predict the experience of interacting with the world around us (e.g., knowing what the hammer will feel like in your hand) and therefore facilitate smooth, goal-directed behavior on the basis of previous experiences. The grounded-cognition theory of desire suggests that such processes of learning and representation also play a role in desire: Appetitive cues trigger

\section{Corresponding Author:}

Esther K. Papies, University of Glasgow, Institute of Neuroscience and Psychology, 62 Hillhead St., Glasgow G12 8QB, United Kingdom

E-mail: esther.papies@glasgow.ac.uk 
consumption and reward simulations, which are based on representations established in previous consumption experiences. These simulations in turn guide motivated behavior, typically without effort and conscious awareness.

According to the theory, each interaction with a food lays down a rich, situated memory (a "situated conceptualization"; Barsalou, 2009, 2016) that integrates various streams of information, such as visual and sensory features (e.g., appearance, taste, texture of a food or drink), contextual features (e.g., time, place, other people present), motor actions (e.g., cutting, grasping, chewing), current states (e.g., hunger, pleasure, health goals), and other information (see Barsalou, 2009). When a relevant cue, such as an image or the smell of a food, later activates this representation, its nonpresent elements can be simulated, or partially "reenacted." This means that, for example, a picture of a piece of cake can lead to a vivid simulation of eating it, including a reexperience of its sweet taste and creamy texture, simulations of motor actions to pick up the fork and eat it, and the anticipation of reward-even when no actual food is present. Such simulations can help predict whether one would like the food and whether one should choose, for example, the chocolate cake or the butterscotch cake. Such simulations are also responsive to state and trait individual differences: They will make a food appear more rewarding in states in which the food has previously been encoded as particularly rewarding (e.g., when hungry; see Papies et al., 2015). Thus, simulations arising from previously stored situated conceptualizations can help one navigate the environment to serve one's goals and can create desire-which may or may not reach conscious awareness.

As an example to illustrate the theory, imagine passing a coffee shop in a new city. You recognize this as a place where you can get different types of coffee, pastries, and sandwiches; where people go to socialize or work while consuming a hot beverage; and where you might hear sounds such as music, people talking, and the coffee grinder and milk steamer. The sight of the coffee shop might be enough for you to think about the taste and mouthfeel of a freshly prepared latte, which might in turn create a craving for coffee-despite your desire to save time and money and to cut down on calories. Once you enter, you know where to go and what to do to obtain coffee. Once you stand in line, viewing the pastries on display triggers simulations of their sweet taste, soft and chewy texture, and the pleasure of eating them, even in the absence of hunger-which may lead to impulsive food choices. In this manner, simulations based on previous experiences help us effortlessly navigate novel environments while also leading to new, potentially problematic desires-certainly in the current obesogenic environment that is full of attractive food temptations.

\section{Appetitive Stimuli Trigger Consumption and Reward Simulations}

A variety of research findings suggest that people represent food and drink through consumption and reward simulations, especially if those foods and drinks are attractive. In one study, participants were asked to list typical features of four attractive foods (e.g., chips, cookies) and four neutral foods (cucumber, rice; Papies, 2013). When describing the attractive foods, they mostly listed words describing taste and texture (e.g., "salty," "crunchy"), hedonic or enjoyment words (e.g., "tasty"), and a wide variety of eating situations (e.g., "at night," "with friends," "TV"; see Fig. 1). For neutral foods, they mostly described visual appearance (e.g., "white," "small," "long") and food production or preparation (e.g., "from Asia," "has to be cooked"). These findings suggest that participants completed the feature-listing task by simulating interacting with the foods. They were more likely to simulate features of eating the attractive food because this had been more strongly encoded as rewarding, compared with the neutral foods, for which other features of experience were more salient. For attractive foods, the number of eating- and enjoymentrelated features also correlated with the rated attractiveness of the foods.

When the same task was administered in the domain of alcoholic drinks (Keesman et al., 2018), participants listed more consumption and enjoyment features for their habitual alcoholic drink, compared with alcohol they did not typically drink and also compared with water. Alcoholic drinks were especially likely to be described in terms of social drinking contexts (e.g., "friends"). Indeed, when asked to list features that were "typically true" of their typical alcoholic drink, participants were more likely to mention social drinking situations than actually liking the drink. Thus, alcoholic drinks are strongly represented in terms of consuming them in social situations.

Further evidence for food cues triggering consumption and reward simulations comes from neuroimaging research. Here, experiments show that when people view food images during a brain scan, this activates the same brain areas that are involved in actual eating, such as primary taste, reward, and motor areas (for reviews, see Chen, Papies, \& Barsalou, 2016; van der Laan, de Ridder, Viergever, \& Smeets, 2011). Again, these activations are especially pronounced for high-calorie foods, suggesting that people simulate eating and enjoyment when they view food pictures, especially when the food looks attractive. 


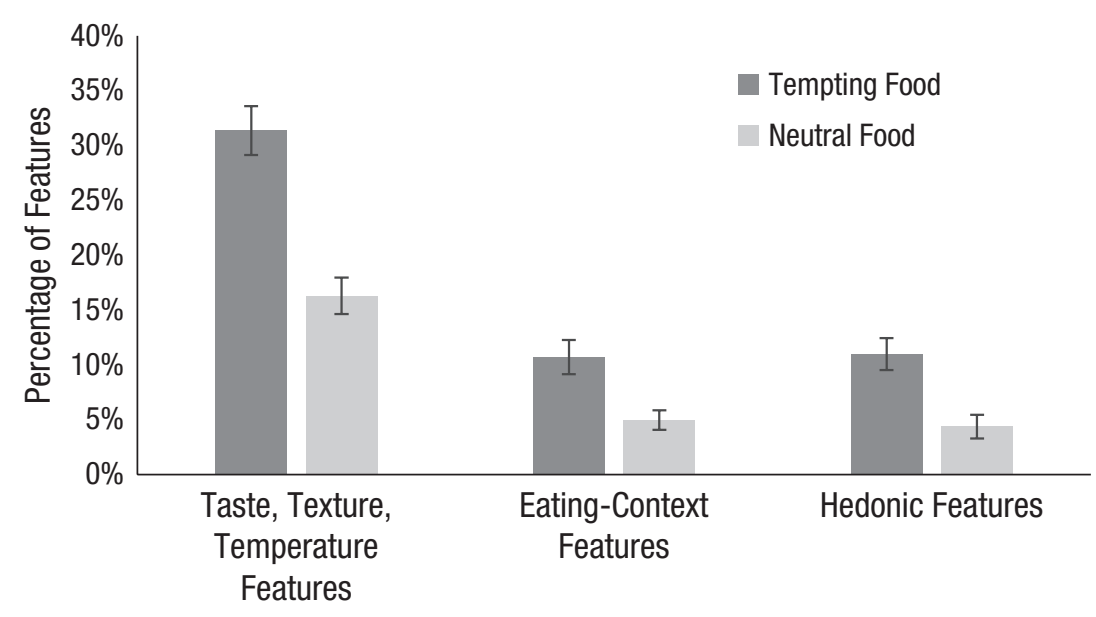

Fig. 1. Percentage of each of three types of eating-simulation features generated for four tempting foods (chips, cookies, cocktail nuts, vanilla ice cream) and four neutral foods (cucumber, apple, banana, rice). Error bars denote standard errors of the mean. Figure adapted from Papies (2013).

\section{Consumption and Reward Simulations Increase Desire}

Research also shows that consumption and reward simulations contribute to desire, again especially for attractive foods and drinks. In the feature-listing study described above (Keesman et al., 2018), participants' desire to consume alcohol was measured by assessing their current alcohol cravings and their intrusive alcohol thoughts in daily life, and then by offering them a voucher for either an alcoholic drink or a nonalcoholic drink. Again, results showed that social-context features for alcoholic drinks were key to understanding participants' desire: These features predicted alcohol cravings, preferences for an alcohol voucher, and intrusive alcohol thoughts. Thus, thinking about alcohol in terms of drinking it in a social context makes it particularly tempting.

Research in which simulations have been manipulated rather than measured also shows that consumption and reward simulations increase desire, using the amount of saliva produced while viewing foods as an implicit measure of desire. In one such study, participants viewed three different food stimuli one at a time (Keesman, Aarts, Vermeent, Häfner, \& Papies, 2016). Half of the participants simply looked at the food for $1 \mathrm{~min}$, whereas the other half vividly imagined or simulated eating it. As the grounded-cognition theory of desire predicts, participants salivated more when they simulated eating the food than when they simply looked at it, especially if the food was attractive.

People do not engage with food and drink stimuli in isolation but in rich, multidimensional situations. The grounded-cognition theory of desire posits that information about these situations is typically stored as part of the situated conceptualizations for consuming food and drink. As a result, situational cues might trigger consumption and reward simulations and therefore increase desire. Indeed, a series of experiments revealed that presenting a food stimulus (e.g., tomato soup) in a congruent eating context (i.e., kitchen table), compared with an incongruent context (e.g., cinema), increased eating simulations, salivation, and desire-independently of hunger (Papies, van Stekelenburg, Smeets, Zandstra, \& Dijksterhuis, 2019). Participants also expected to like the food more when it was presented in a congruent context, with eating simulations ("I imagined that I was eating the ...") mediating the effect of context on liking and desire. Thus, processing a food in a context where one would typically eat it increases thoughts of what the food will taste and feel like, which in turn makes it more attractive.

Eating simulations that shape desire and liking can be triggered not only by the food itself and by context cues but also by labels and descriptions of food and drink. Turnwald and Crum (2019), for example, have shown that using food labels that emphasize sensory and hedonic features (e.g., "crispy," "decadent") rather than health features (e.g., "fiber-packed," "nutritious") increased choices of and liking of vegetable-based dishes-presumably because such labels triggered rewarding consumption simulations, which then affected actual eating experiences. Conversely, work on how to best present healthier versions of common products has shown that emphasizing healthy features (e.g., low salt or low fat) reduces liking, compared with presenting the same products without such labels (e.g., Liem, Miremadi, Zandstra, \& Keast, 2012), again presumably because such labels trigger simulations of 
eating a rather bland food. In neuroimaging research, when participants tasted a savory solution labeled as having a "rich and delicious flavor," they liked it more, and this was associated with stronger associated reward activations in the brain, compared with tasting the same solution labeled as "boiled vegetable water" (Grabenhorst, Rolls, \& Bilderbeck, 2008). Similarly, wine labeled with a higher price was rated as tastier than wine labeled with a lower price, further producing stronger activations in brain regions associated with pleasantness (Plassmann, O'Doherty, Shiv, \& Rangel, 2008). Finally, the label "extra sweet" compared with "less sweet" on an orange juice led to higher sweetness ratings and stronger activations in primary taste areas, even though the juices participants tasted were exactly the same (Woods et al., 2011). Together, these findings suggest that labels trigger specific sensory and reward simulations in the brain, which are experienced as expectancies about what a food will taste and feel like and which then assimilate the taste perception and consumption experience (for similar effects in the domain of color, see Hansen, Olkkonen, Walter, \& Gegenfurtner, 2006).

Finally, eating simulations and desire can also be affected by simulations of the motor behavior involved in eating. As an example, when the fork next to a piece of apple pie faces the dominant hand of the perceiver, eating simulations and purchase intentions are higher than when it faces the other way, because one can more easily simulate eating. However, when the dominant hand is blocked by an experimental manipulation (e.g., pressing a clamp with the dominant hand), the direction of the fork no longer matters (Elder \& Krishna, 2012), presumably because simulating picking it up to eat the food then becomes more difficult, which in turn curbs the effect on desire.

In sum, eating simulations resulting from appetitive stimuli, contextual cues, food labels, and motor cues play a key role in desire. Importantly, intervention strategies that target these simulations have the potential to tame desire.

\section{Targeting Consumption and Reward Simulations Can Reduce Desire}

One promising intervention strategy to diffuse consumption and reward simulations comes from mindfulness research. Often referred to as decentering or dereification, brief interventions that teach people to observe their responses to appetitive stimuli (i.e., their simulations) as "mere mental events" can reduce approach impulses, unhealthy choices, food cravings, and 5-day chocolate consumption (e.g., Baquedano et al., 2017; Jenkins \& Tapper, 2014; Papies, Barsalou, \& Custers, 2012; Papies et al., 2015). Recent work suggests that this strategy is effective not because it reduces simulations themselves but because it reduces their effect on desire (in this case, salivation; Keesman, Aarts, Häfner, \& Papies, 2020).

A different strategy is to directly reduce the working memory resources available to activate consumption and reward simulations (Van Dillen, Papies, \& Hofmann, 2013) or, once full-blown cravings have developed, to load the working memory capacity needed to maintain and elaborate conscious consumption and reward imagery (e.g., Hamilton, Fawson, May, Andrade, \& Kavanagh, 2013). These strategies follow from research showing that the conscious-consumption imagery underlying food cravings requires working memory capacity, especially its visual subcomponent (Harvey, Kemps, \& Tiggemann, 2005). Exactly how working memory capacity affects nonconscious simulations, and more generally to what degree consumption and reward simulations exhibit features of automaticity, is not yet fully understood. So far, however, research on decentering and working memory suggests that targeting consumption and reward simulations can prevent or diffuse desire.

\section{Conclusions}

We have seen that people spontaneously think about foods and drinks in terms of what it feels like to consume them and that these thoughts contribute to desire. In other words, consumption and reward simulations, triggered by a variety of appetitive and context cues, can lead to desire for food and drink, thereby interfering with self-regulation in the pursuit of long-term goals. Future research should integrate this perspective with research on other cognitive processes in eating to examine, for example, how simulations interact with attentional biases that affect eating (e.g., Kaisari et al., 2019) and how new episodic eating memories update representations that affect simulations and desires (Higgs \& Spetter, 2018).

This body of evidence is consistent with research on the roles of simulations in cognitive processes more generally, which has shown that we use modality-specific knowledge from previous experiences to understand and navigate the complex world around us. Indeed, simulations of possible actions and interactions have been shown to play a role throughout central areas of psychology, for example, in prejudice reduction, prosocial behavior, action control, and episodic future thinking (e.g., Atance \& O'Neill, 2001; Crisp \& Turner, 2009; Gaesser, Shimura, \& Cikara, 2020), and they are likely to also play a role in consumer behavior more generally. Thus, it is not surprising that simulations also affect motivated behavior in the domain of health. In the future, researchers could aim to establish a general 
account of simulation in motivated behavior in order to better understand the learning processes that establish the situated representations underlying these simulations and to examine how they can be shaped to facilitate healthy, sustainable, and prosocial behaviors.

\section{Recommended Reading}

Chen, J., Papies, E. K., \& Barsalou, L. W. (2016). (See References). Reviews and discusses brain-imaging studies examining responses to food cues from the perspective of grounded cognition.

Hofmann, W., Vohs, K. D., \& Baumeister, R. F. (2012). (See References). A modern classic describing the types of desire people experience and try to regulate in everyday life.

Kavanagh, D. J., Andrade, J., \& May, J. (2005). Imaginary relish and exquisite torture: The elaborated intrusion theory of desire. Psychological Review, 112, 446-467. Argues that sensory imagery contributes to desire through conscious and elaborated cognitive processes, an alternative view to the one presented in the current article.

Papies, E. K. (2020). (See References). A more detailed presentation of the grounded-cognition theory of desire, as well as an overview of ongoing work.

Papies, E. K., Pronk, T. M., Keesman, M., \& Barsalou, L. W. (2015). (See References). Discusses the role of individual differences in grounded cognitive processes in desire in more detail than the current article does and shows how their effects can be modulated by a mindfulness-based intervention.

\section{Transparency}

Action Editor: Randall W. Engle

Editor: Randall W. Engle

Declaration of Conflicting Interests

The author(s) declared that there were no conflicts of interest with respect to the authorship or the publication of this article.

\section{ORCID iDs}

Esther K. Papies (iD https://orcid.org/0000-0002-8460-675X Lawrence W. Barsalou (iD https://orcid.org/0000-0002-1232-3152

\section{References}

Atance, C. M., \& O'Neill, D. K. (2001). Episodic future thinking. Trends in Cognitive Sciences, 5, 533-539. doi:10.1016/ S1364-6613(00)01804-0

Baquedano, C., Vergara, R., Lopez, V., Fabar, C., Cosmelli, D., \& Lutz, A. (2017). Compared to self-immersion, mindful attention reduces salivation and automatic food bias. Scientific Reports, 7(1), Article 13839. doi:10.1038/s41598017-13662-Z

Barsalou, L. W. (2008). Grounded cognition. Annual Review of Psychology, 59, 617-645.

Barsalou, L. W. (2009). Simulation, situated conceptualization, and prediction. Philosophical Transactions of the
Royal Society B: Biological Sciences, 364, 1281-1289. doi:10.1098/rstb.2008.0319

Barsalou, L. W. (2016). Situated conceptualization offers a theoretical account of social priming. Current Opinion in Psychology, 12, 6-11.

Chen, J., Papies, E. K., \& Barsalou, L. W. (2016). A core eating network and its modulations underlie diverse eating phenomena. Brain and Cognition, 110, 20-42. doi:10.1016/j bandc.2016.04.004

Crisp, R. J., \& Turner, R. N. (2009). Can imagined interactions produce positive perceptions? Reducing prejudice through simulated social contact. American Psychologist, 64, 231-240. doi:10.1037/a0014718

Elder, R. S., \& Krishna, A. (2012). The "visual depiction effect" in advertising: Facilitating embodied mental simulation through product orientation. Journal of Consumer Research, 38, 988-1003. doi:10.1086/661531

Gaesser, B., Shimura, Y., \& Cikara, M. (2020). Episodic simulation reduces intergroup bias in prosocial intention and behavior. Journal of Personality and Social Psychology, 118, 683-705. doi:10.1037/pspi0000194

Grabenhorst, F., Rolls, E. T., \& Bilderbeck, A. (2008). How cognition modulates affective responses to taste and flavor: Top-down influences on the orbitofrontal and pregenual cingulate cortices. Cerebral Cortex, 18, 1549-1559. doi:10.1093/cercor/bhm185

Hamilton, J., Fawson, S., May, J., Andrade, J., \& Kavanagh, D. J. (2013). Brief guided imagery and body scanning interventions reduce food cravings. Appetite, 71, 158-162. doi:10.1016/j.appet.2013.08.005

Hansen, T., Olkkonen, M., Walter, S., \& Gegenfurtner, K. R. (2006). Memory modulates color appearance. Nature Neuroscience, 9, 1367-1368. doi:10.1038/nn1794

Harvey, K., Kemps, E., \& Tiggemann, M. (2005). The nature of imagery processes underlying food cravings. British Journal of Health Psychology, 10, 49-56. doi:10.1348/ $135910704 X 14249$

Higgs, S., \& Spetter, M. S. (2018). Cognitive control of eating: The role of memory in appetite and weight gain. Current Obesity Reports, 7, 50-59. doi:10.1007/s13679-018-0296-9

Hofmann, W., Vohs, K. D., \& Baumeister, R. F. (2012). What people desire, feel conflicted about, and try to resist in everyday life. Psychological Science, 23, 582-588. doi: $10.1177 / 0956797612437426$

Jenkins, K. T., \& Tapper, K. (2014). Resisting chocolate temptation using a brief mindfulness strategy. British Journal of Health Psychology, 19, 509-522. doi:10.1111/bjhp.12050

Kaisari, P., Kumar, S., Hattersley, J., Dourish, C. T., Rotshtein, P., \& Higgs, S. (2019). Top-down guidance of attention to food cues is enhanced in individuals with overweight/ obesity and predicts change in weight at one-year follow up. International Journal of Obesity, 43, 1849-1858. doi:10 .1038/s41366-018-0246-3

Keesman, M., Aarts, H., Häfner, M., \& Papies, E. K. (2020). The decentering component of mindfulness reduces reactions to mental imagery. Motivation Science, 61, 34-42.

Keesman, M., Aarts, H., Ostafin, B. D., Verwei, S., Häfner, M., \& Papies, E. K. (2018). Alcohol representations are socially situated: An investigation of beverage representations by 
using a property generation task. Appetite, 120, 654-665. doi:10.1016/j.appet.2017.10.019

Keesman, M., Aarts, H., Vermeent, S., Häfner, M., \& Papies, E. K. (2016). Consumption simulations induce salivation to food cues. PLOS ONE, 11(11), Article e0165449. doi:10.1371/journal.pone.0165449

Liem, D. G., Miremadi, F., Zandstra, E. H., \& Keast, R. S. (2012). Health labelling can influence taste perception and use of table salt for reduced-sodium products. Public Health Nutrition, 15, 2340-2347. doi:10.1017/S1368980012 00064X

Martin, A., Wiggs, C. L., Ungerleider, L. G., \& Haxby, J. V. (1996). Neural correlates of category-specific knowledge. Nature, 379, 649-652. doi:10.1038/379649a0

Papies, E. K. (2013). Tempting food words activate eating simulations. Frontiers in Psychology, 4, Article 838. doi:10.3389/fpsyg. 2013.00838

Papies, E. K. (2020). Grounding desire: The role of consumption and reward simulations in eating and drinking behaviour. In J. P. Forgas, W. D. Crano, \& K. Fiedler (Eds.), Applications of social psychology: How social psychology can contribute to the solution of real-world problems (pp. 142-160). New York, NY: Routledge.

Papies, E. K., \& Barsalou, L. W. (2015). Grounding desire and motivated behavior: A theoretical framework and review of empirical evidence. In W. Hofmann \& L. F. Nordgren (Eds.), The psychology of desire (pp. 36-60). New York, NY: Guilford Press.

Papies, E. K., Barsalou, L. W., \& Custers, R. (2012). Mindful attention prevents mindless impulses. Social Psychological and Personality Science, 3, 291-299. doi:10.1177/194855061 1419031

Papies, E. K., Best, M., Gelibter, E., \& Barsalou, L. W. (2017). The role of simulations in consumer experiences and behavior: Insights from the grounded cognition theory of desire. Journal of the Association for Consumer Research, 2, 402-418. doi:10.1086/693110

Papies, E. K., Pronk, T. M., Keesman, M., \& Barsalou, L. W. (2015). The benefits of simply observing: Mindful attention modulates the link between motivation and behavior. Journal of Personality and Social Psychology, 108, 148170. doi:10.1037/a0038032

Papies, E. K., van Stekelenburg, A., Smeets, M. A. M., Zandstra, L., \& Dijksterhuis, G. B. (2019). Situating desire: Context cues increase desire for food through eating simulations. Manuscript submitted for publication.

Plassmann, H., O'Doherty, J., Shiv, B., \& Rangel, A. (2008). Marketing actions can modulate neural representations of experienced pleasantness. Proceedings of the National Academy of Sciences, USA, 105, 1050-1054. doi:10.1073/ pnas.0706929105

Turnwald, B. P., \& Crum, A. J. (2019). Smart food policy for healthy food labeling: Leading with taste, not healthiness, to shift consumption and enjoyment of healthy foods. Preventive Medicine, 119, 7-13. doi:10.1016/j.ypmed .2018.11.021

van der Laan, L. N., de Ridder, D. T. D., Viergever, M. A., \& Smeets, P. A. M. (2011). The first taste is always with the eyes: A meta-analysis on the neural correlates of processing visual food cues. NeuroImage, 55, 296-303. doi:10.1016/j.neuroimage.2010.11.055

Van Dillen, L. F., Papies, E. K., \& Hofmann, W. (2013). Turning a blind eye to temptation: How task load can facilitate self-regulation. Journal of Personality and Social Psychology, 104, 427-443.

Woods, A. T., Lloyd, D. M., Kuenzel, J., Poliakoff, E., Dijksterhuis, G. B., \& Thomas, A. (2011). Expected taste intensity affects response to sweet drinks in primary taste cortex. NeuroReport, 22, 365-369. doi:10.1097/ WNR.0b013e3283469581 